\title{
Multiple pregnancies with complete mole and coexisting normal fetus in North and South America: A retrospective multicenter cohort and literature review
}

\author{
Lawrence H. Lin ${ }^{\text {a }}$, Izildinha Maestá ${ }^{b}$, Antonio Braga ${ }^{c}$, Sue Y. Sun ${ }^{\text {d }}$, Koji Fushida ${ }^{\text {a }}$, Rossana P.V. Francisco ${ }^{\text {, }}$ \\ Kevin M. Elias ${ }^{\text {ef,g,h, }}$, Neil Horowitz ${ }^{\text {ef,g,h, }}$, Donald P. Goldstein ${ }^{\text {e,f,g,h }}$, Ross S. Berkowitz ${ }^{\text {e,f,g,h,* }}$ \\ a University of Sao Paulo Trophoblastic Disease Center, University of Sao Paulo Medical School, Sao Paulo, Sao Paulo, Brazil \\ b Botucatu Trophoblastic Disease Center, Clinical Hospital of Botucatu Medical School, Sao Paulo State University, Botucatu, Sao Paulo, Brazil

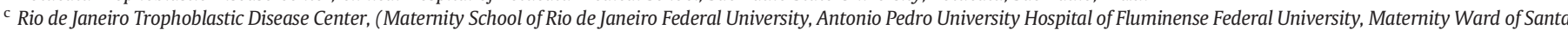 \\ Casa da Misericórdia do Rio de Janeiro), Rio de Janeiro, Rio de Janeiro, Brazil \\ d Sao Paulo Hospital Trophoblastic Disease Center, Paulista School of Medicine, Sao Paulo Federal University, Sao Paulo, Sao Paulo, Brazil \\ e New England Trophoblastic Disease Center, Donald P. Goldstein MD, Trophoblastic Tumor Registry, Boston, MA, USA \\ ${ }^{\mathrm{f}}$ Division of Gynecologic Oncology, Brigham and Women's Hospital, Boston, MA, USA \\ ${ }^{g}$ Department of Obstetrics, Gynecology and Reproductive Biology, Harvard Medical School, Boston, MA, USA \\ h Dana Farber Cancer Institute, Boston, MA, USA
}

\section{H I G H L I G H T S}

- Pregnancies with mole and fetus in South America presented with more complications.

- Pregnancies with mole and fetus were at high risk for persistent disease.

- Elective termination did not influence risk of persistent disease.

\section{A R T I C L E I N F O}

\section{Article history:}

Received 28 December 2016

Received in revised form 12 January 2017

Accepted 19 January 2017

Available online 26 January 2017

Keywords:

Gestational trophoblastic disease

Hydatidiform mole

Pregnancy, Twin

Multiple, Pregnancy

Trophoblastic neoplasms

Near miss, healthcare

\section{A B S T R A C T}

Objective. To determine the clinical characteristics of multiple gestation with complete mole and coexisting fetus (CHMCF) in North and South America.

Methods. Retrospective non-concurrent cohorts compromised of CHMCF from New England Trophoblastic Disease Center (NETDC) (1966-2015) and four Brazilian Trophoblastic Disease Centers (BTDC) (1990-2015).

Results. From a total of 12,455 cases of gestational trophoblastic disease seen, 72 CHMCF were identified. Clinical characteristics were similar between BTDC $(n=46)$ and NETDC $(n=13)$ from 1990 to 2015, apart from a much higher frequency of potentially life-threatening conditions in Brazil $(p=0.046)$. There were no significant changes in the clinical presentation or outcomes over the past 5 decades in NETDC ( 13 cases in 1966-1989 vs 13 cases in 1990-2015). Ten pregnancies were electively terminated and 35 cases resulted in viable live births (60\% of 60 continued pregnancies). The overall rate of gestational trophoblastic neoplasia (GTN) was $46 \%$; the cases which progressed to GTN presented with higher chorionic gonadotropin levels $(p=0.026)$ and higher frequency of termination of pregnancy due to medical complications $(p=0.006)$ when compared to those with spontaneous remission.

Conclusions. The main regional difference in CHMCF presentation is related to a higher rate of potentially lifethreatening conditions in South America. Sixty percent of the expectantly managed CHMCF delivered a viable infant, and the overall rate of GTN in this study was $46 \%$. Elective termination of pregnancy did not influence the risk for GTN; however the need for termination due to complications and higher hCG levels were associated with development of GTN in CHMCF.

(c) 2017 Elsevier Inc. All rights reserved.

\footnotetext{
* Corresponding author at: Brigham and Womens' Hospital, 75 Francis Street, Boston, MA 02115, USA
}

E-mail address: rberkowitz@partners.org (R.S. Berkowitz). 


\section{Introduction}

Multiple gestation with a complete mole and coexisting fetus (CHMCF) is a rare event, with an estimated incidence of 1 case for 20,000-100,000 pregnancies [1-3]. These pregnancies are characterized by the coexistence of a complete mole and a potentially viable fetus with a normal placenta, in contrast to partial moles, which are composed of a single triploid conceptus with an abnormal placenta [4]. The differential diagnosis is important due to the fact that a partial mole's fetus is nonviable and the gestational trophoblastic neoplasia (GTN) risk is $<5 \%$ [5]. There is still controversy on the rate of GTN progression in CHMCF, with varying rates of GTN being reported [1,6-9].

CHMCF are classically associated with several pregnancy complications, such as spontaneous abortions, intrauterine deaths, preeclampsia and hyperthyroidism $[2,6,7]$. In the past, due to the uncertain behavior of these pregnancies, they were commonly advised to be terminated, leaving little information on the natural history of this condition. One large study on CHMCF has shown that there is no association between elective pregnancy termination and the rate of GTN; similarly in single moles, gestational age of evacuation does not influence the progression to GTN $[1,10]$.

A recent collaborative study described different characteristics of complete molar pregnancy in adolescents in North and South America, showing that regional differences may play a role in the clinical presentation of complete mole [11]. The reports around the globe describing clinical presentation and GTN risk of CHMCF are conflicting, either due to differences in hospital-based versus population-based data or actual regional differences on disease behavior. The aim of this study was to determine the clinical characteristics of CHMCF in North and South America and provide additional information on the natural history of this condition.

\section{Methods}

\subsection{Study design and setting}

This is a retrospective cohort study consisting of all multiple pregnancies with complete mole and coexisting fetus registered at the New England Trophoblast Disease Center (NETDC) from 1966 to 2015 and 4 Brazilian Trophoblastic Disease Reference Centers (Botucatu Trophoblastic Disease Center, Rio de Janeiro Trophoblastic Disease Center, Sao Paulo Hospital Trophoblastic Disease Center and University of Sao Paulo Trophoblastic Disease Center; all located in the southeast region of Brazil) from 1990 to 2015. This study was approved by the centers' respective institutional review boards and the manuscript was drafted in accordance with STROBE guidelines [12].

All electronic and paper charts for the patients were reviewed. The diagnosis of CHMCF was confirmed by histological evaluation by experienced pathologists in all cases. In cases with uncertain histological diagnosis, additional p57 $7^{\mathrm{KI} 2}$ immunostaining, ploidy or/and cytogenetic analysis was also performed. Patients with a diagnosis of partial mole or placental mesenchymal dysplasia were excluded from this study.

The patients were compared regarding: regional location (NETDC vs Brazil) from 1990 to 2015; current cohort (1990-2015) vs historical cohort (1966-1989) in NETDC; GTN progression vs spontaneous regression (all cohorts' data). For temporally concurrent comparisons, a recently published NETDC cohort on single complete moles (19942013) was compared to the NETDC CHMCF cohort (1990-2015) and all CHMCF data in recent years (1990-2015) [10].

\subsection{Variables and definitions}

The following variables were abstracted: pregnancy presentation, medical complications, obstetric outcomes, GTN progression and treatment, potentially life-threatening conditions and maternal near miss complications. Due to the nature of referral centers, some patients were outside consults without complete follow-up; patients with missing information were included only in analyses of variables for which data were available. All patients followed in the referral centers were assisted during the course of pregnancy by maternal fetal medicine and trophoblastic disease team specialists.

Medical complications evaluated in this study included vaginal hemorrhage, preeclampsia, clinical hyperthyroidism and respiratory distress. Vaginal hemorrhage was defined as excessive vaginal bleeding leading to hospitalization, hemodynamic instability, blood transfusion or termination of pregnancy. Preeclampsia was defined as hypertension (systolic blood pressure $\geq 140 \mathrm{~mm} \mathrm{Hg}$ and/or diastolic blood pressure $\geq 90 \mathrm{~mm} \mathrm{Hg}$ ) associated with proteinuria on dipstick or at least $300 \mathrm{mg}$ in $24 \mathrm{~h}$. Clinical hyperthyroidism was characterized as suppressed thyroid-stimulating hormone (TSH) with elevated serum free thyroxine (T4) levels in the presence of classical symptoms (such as tachycardia, tremor or elevated body temperature) or the need to be treated with beta-blocker. Respiratory distress was defined when the patient presented with acute tachypnea or dyspnea with a radiographic pulmonary infiltrate or pleural effusion. World Health Organization (WHO) defines a maternal near miss as "a woman who nearly died but survived a complication that occurred during pregnancy, childbirth, or within 42 days of termination of pregnancy". Potentially life-threatening conditions and maternal near miss were established using the WHO criteria and classification [13]. According to the WHO recommendations on interventions to improve preterm birth outcome guideline, fetal viability depends on the local resources and before 24 weeks the chance of survival without considerable morbidity is low even in highresource settings; therefore, viable pregnancies were considered the ones in which live infants were delivered at least at 24 weeks of gestational age [14].

After the end of pregnancy the patients were followed with weekly serum human chorionic gonadotropin (hCG) measurements until normal values were achieved and then with monthly values up to 6 months. All reference centers used hCG detection kits based on chemiluminescent methods with a sensitivity of at least $5 \mathrm{mIU} / \mathrm{mL}$. In cases where the hCG was above the detection range of the method, the highest recorded value was identified. The patients were diagnosed with GTN if they presented with at least one of the following FIGO (2002) diagnostic criteria: (1) rise of at least 10\% of hCG levels in 3 weekly measurements, (2) plateau ( $<10 \%$ variation) for 4 weekly values of hCG, (3) metastatic disease in the presence of positive hCG, (4) histological diagnosis of choriocarcinoma. Patients with GTN were staged according to the FIGO (2002) anatomic and prognostic system [15]. Remission was classified as the normalization of hCG levels for at least 3 consecutive weeks. Resistance was defined as a variation $<10 \%$ in 3 consecutive weekly hCG levels or the rise of $>10 \%$ in 2 weekly values of hCG during chemotherapy. Recurrence was characterized as hCG elevation after remission of disease after completion of chemotherapy in the absence of a new pregnancy.

\subsection{Statistical methods}

The results were analyzed in means \pm standard deviation for quantitative variables and in proportions for qualitative variables. The means were compared using the unpaired Student's $t$-test for normally distributed variables and a Mann-Whitney test for variables with non-normal distribution, while proportions were analyzed using Fisher's exact test. A p value $<0.05$ was considered statistically significant. The results were all shown as medians in the tables of this manuscript because of the non-normal distribution they displayed.

\subsection{Literature review}

A literature review was performed by searching in Medline, Pubmed and EMBASE databases for cohort studies or case series related to $\mathrm{CHMCF}$ in the literature, using the following MeSH (Medical Subject 
Headings) terms: [("Gestational Trophoblastic Disease" OR "Hydatidiform Mole") AND ("Pregnancy, Twin" OR "Multiple, Pregnancy")]. Studies in the English language composed of $>5$ cases published between 1990 and 2016 and that displayed information on clinical presentation, pregnancy outcomes and GTN progression were included in the review. Conference communications regarding updated information on previously published series were also included in this review.

\section{Results}

The complete study cohort consisted of 72 cases of CHMCF ( 46 cases from BTDC, 13 cases from the NETDC historical cohort and 13 cases from the NETDC current cohort). The overview of demographic and clinical information of the patients included is presented in Table 1. Seventy pregnancies consisted of multiple pregnancies with a complete mole and a coexisting normal fetus, one case in BTDC included a complete mole and two coexisting fetuses and another case in NETDC was composed by a complete mole, a normal fetus and a blighted ovum. Thirteen percent of the cases were related to assisted reproductive technologies (ART).

When comparing data from BTDC and NETDC from 1990 to 2015, most clinical characteristics (clinical presentation, diagnosis, obstetric outcome and GTN progression) were similar (Table 2). The rate of potentially life-threatening conditions in BTDC was significantly higher than in NETDC ( $63 \%$ in BTDC vs $30 \%$ in NETDC, $p=0.046$ ). Although the difference in near-miss events was not significant, there was not a single case of maternal near-miss event in NETDC compared to a

Table 1

Demographic, clinical characteristics and outcomes of the study population.

\begin{tabular}{|c|c|}
\hline Number of cases $(n)$ & 72 \\
\hline \multicolumn{2}{|l|}{ Location, $\mathrm{n}(\%)$} \\
\hline Brazilian Trophoblastic Disease Centers & $46(64 \%)$ \\
\hline New England Trophoblastic Disease Center & $26(36 \%)$ \\
\hline Age, median (minimum-maximum) & $28.5(18-41)^{a}$ \\
\hline Gravidity, median & $2(1-5)^{b}$ \\
\hline Parity, median & $0(0-4)^{b}$ \\
\hline Previous mole, $\mathrm{n}(\%)$ & $3(4 \%)^{b}$ \\
\hline Assisted reproduction treatment, n (\%) & $9(13 \%)^{\mathrm{a}}$ \\
\hline $\begin{array}{l}\text { Gestational age at diagnosis, weeks, median } \\
\text { (minimum-maximum) }\end{array}$ & $15(9-30)^{\mathrm{c}}$ \\
\hline $\begin{array}{l}\text { Gestational age at the end of pregnancy, weeks, median } \\
\text { (minimum-maximum) }\end{array}$ & $24(11-40)^{\mathrm{d}}$ \\
\hline $\begin{array}{l}\text { hCG levels at diagnosis, } \mathrm{mIU} / \mathrm{mL} \text {, median } \\
\text { (minimum-maximum) }\end{array}$ & $\begin{array}{l}400,000 \\
(1048-2,469,000)^{\mathrm{e}}\end{array}$ \\
\hline $\begin{array}{l}\text { hCG levels at the end of pregnancy, } \mathrm{mIU} / \mathrm{mL} \text {, median } \\
\text { (minimum-maximum) }\end{array}$ & $\begin{array}{l}200,000 \\
(1048-1,670,600)^{\mathrm{f}}\end{array}$ \\
\hline Cytogenetic or ploidy analysis, $\mathrm{n}(\%)$ & $30(54 \%)^{\mathrm{g}}$ \\
\hline Medical complications, $\mathrm{n}(\%)$ & $41(63 \%)^{\mathrm{h}}$ \\
\hline \multicolumn{2}{|l|}{ Termination of pregnancy before 24 weeks, $n(\%)^{a}$} \\
\hline Elective termination & $10(14 \%)$ \\
\hline Termination due to medical complications & $7(10 \%)$ \\
\hline No termination & $53(76 \%)$ \\
\hline \multicolumn{2}{|l|}{ Pregnancy outcomes, $\mathrm{n}(\%)^{\mathrm{a}}$} \\
\hline Miscarriage & $11(16 \%)$ \\
\hline Intrauterine death & $6(8 \%)$ \\
\hline Preterm delivery & $25(36 \%)$ \\
\hline Term delivery & $11(16 \%)$ \\
\hline Termination of pregnancy & $17(24 \%)$ \\
\hline Fetal viability, $\mathrm{n}(\%)$ & $34(49 \%)^{b}$ \\
\hline GTN progression, n (\%) & $31(46 \%)^{i}$ \\
\hline Maternal death, $\mathrm{n}(\%)$ & $1(1.4 \%)$ \\
\hline
\end{tabular}

hCG: human chorionic gonadotropin hormone; GTN: gestational trophoblastic neoplasia.

a Information not available in 2 patients.

b Information not available in 3 patients.

c Information not available in 7 patients.

d Information not available in 5 patients.

e Information not available in 12 patients.

$\mathrm{f}$ Information not available in 15 patients.

$\mathrm{g}$ Information not available in 6 patients.

$\mathrm{h}$ Information not available in 9 patients.

${ }^{\mathrm{i}}$ Information not available in 4 patients.
$21.7 \%$ rate in BTDC $(p=0.18)$. Even though the frequency of hysterotomies was higher in Brazil ( $p=0.015$ ), the rate of GTN progression was the same between the two groups.

Data examining the clinical course of CHMCF compared over five decades at NETDC are presented in Table S1. There was no difference between the two time periods in NETDC (1990-2015 vs 1966-1989) regarding clinical characteristics or outcome.

Since there were no significant differences in the obstetric outcomes between the NETDC and BTDC cohorts, we combined these data to summarize the outcome of 70 cases of CHMCF (Fig. 1): in 2 cases the information on pregnancy outcome was not available, 10 cases were electively terminated in the first trimester, 36 viable infants were delivered alive (60\% of the 60 continued pregnancies), 7 patients had pregnancy terminations due to severe pregnancy complications before fetal viability ( $12 \%$ of the 60 continued pregnancies), 17 cases were not viable pregnancies (28\% of the 60 continued pregnancies were either spontaneous abortions, intrauterine deaths or extreme preterm deliveries before viability). There were no cases of fetal demise after 24 weeks of gestational age. Sixty-nine percent of the live births were preterm deliveries.

In the combined cohort, the overall rate of GTN was $46 \%$; the cases which developed GTN $(\mathrm{n}=31)$ presented with higher hCG levels $(250,000 \mathrm{mIU} / \mathrm{mL}$ vs $120,000 \mathrm{mIU} / \mathrm{mL} \mathrm{p}=0.026)$, lower gestational age (17 weeks vs 28.5 weeks, $\mathrm{p}<0.001$ ) at the end of pregnancy, lower fetal viability rates ( $27 \%$ vs $68 \%, \mathrm{p}=0.001$ ) and higher need for termination of pregnancy due to pregnancy complications ( $20 \%$ vs $0 \%$, $\mathrm{p}=0.006$ ) when compared to those with spontaneous remission $(\mathrm{n}=37)$ (Table 3$)$. No patients were given prophylactic chemotherapy nor were they subjected to a second uterine evacuation.

To compare the outcomes between twin and singleton molar pregnancies, data from a published study on single complete moles from NETDC (1994-2013) was compared to the CHMCF cases at the NETDC in a similar timeframe (1990-2015) (Table S2) [5,16]. Due to a similar presentation of CHMCF in NETDC and BTDC between 1990 and 2015, the data was combined to increase statistical power of the analysis for the comparison with single complete moles from NETDC (1994-2013) (Table 4). In both analyses, there was a statistically significant higher gestational age of diagnosis, gestational age at the end of pregnancy, preeclampsia and potentially life-threatening conditions rate in CHMCF than in single complete moles (Table 4 and Table S2). The combined data from NETDC and BTDC from 1990 and 2015 also showed higher levels of hCG at diagnosis $(\mathrm{p}<0.001)$, higher rate of clinical hyperthyroidism ( $p=0.0003$ ), higher frequency of maternal near miss events ( $p=0.0001)$ and risk of GTN ( $p=0.0001)$ when compared to single complete moles. Although not quite reaching statistical significance ( $p=0.0625$ ), the rate of progression to GTN in CHMCF in NETDC seemed to be higher (42\%) than in the single moles (18\%).

\section{Discussion}

There is still controversy about disease presentation, obstetric outcomes and GTN progression concerning CHMCF, due to the rarity of this entity and different reports around the world. In this current work, the regional differences in $\mathrm{CHMCF}$ were addressed by comparing cohorts from Referral Centers in Brazil and United States of America in the same time period (1990-2015). Most of the variables were not different, except for the higher frequency of potentially life-threatening conditions in Brazil. In single complete moles, more complications are expected when there is a later diagnosis of molar pregnancy, which would not explain the difference seen in this study, since gestational age at diagnosis and at the end of pregnancy were similar in BTDC and NETDC [17]. This increased frequency of potentially life-threatening conditions in Brazil also could not be accounted only to healthcare access, since the rate of elective pregnancy terminations were similar and some of the conditions in the WHO classification may not be preventable in CHMCF (e.g. trophoblastic embolization, thrombocytopenia). A plausible explanation for this 
Table 2

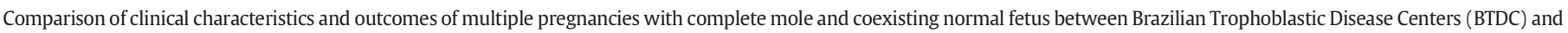
New England Trophoblastic Disease Center (NETDC) from 1990 to 2015.

\begin{tabular}{|c|c|c|c|}
\hline & $\begin{array}{l}\text { NETDC } \\
1990-2015\end{array}$ & $\begin{array}{l}\text { BTDC } \\
1990-2015\end{array}$ & $\mathrm{p}$ value \\
\hline Number of cases & 13 & 46 & \\
\hline Age, median (minimum-maximum) & $34(18-41)$ & $28(18-41)$ & 0.067 \\
\hline Gravidity, median (minimum-maximum) & $2(1-5)$ & $1.5(1-5)$ & 0.028 \\
\hline Parity, median (minimum-maximum) & $1(0-3)$ & $0(0-4)$ & 0.180 \\
\hline Previous mole, $\mathrm{n}(\%)$ & $1(8 \%)$ & $1(2 \%)$ & 0.395 \\
\hline Assisted reproduction treatment, $\mathrm{n}(\%)$ & $2(15 \%)$ & $5(11 \%)$ & 0.648 \\
\hline Gestational age at diagnosis, weeks, median (minimum-maximum) & $15(12-22)^{a}$ & $15(9-23)$ & \\
\hline Gestational age at the end of pregnancy, weeks, median (minimum-maximum) & $21(11-38)^{a}$ & $25(13-40)$ & 0.708 \\
\hline hCG levels at diagnosis, $\mathrm{mIU} / \mathrm{mL}$, median (minimum-maximum) & $221,331(34,366-1.365 .080)^{\mathrm{b}}$ & $500,000(2545-2,052,500)^{\mathrm{b}}$ & 0.142 \\
\hline hCG levels at end of pregnancy, mIU/mL, median (minimum-maximum) & $114,633(18,361-1,365,080)^{\mathrm{c}}$ & $210,000(28,764-1,670,600)^{\mathrm{c}}$ & 0.183 \\
\hline Cytogenetic or ploidy analysis, $\mathrm{n}(\%)$ & $9(82 \%)^{\mathrm{a}}$ & $22(48 \%)$ & 0.051 \\
\hline Medical complications, $\mathrm{n}(\%)$ & $6(60 \%)^{c}$ & $32(70 \%)$ & 0.711 \\
\hline Vaginal hemorrhage, $\mathrm{n}(\%)$ & $5(50 \%)^{c}$ & $31(67 \%)$ & 0.468 \\
\hline Preeclampsia, n (\%) & $3(30 \%)^{c}$ & $17(35 \%)$ & 0.511 \\
\hline Clinical hyperthyroidism, n (\%) & $0(0 \%)^{c}$ & $9(20 \%)$ & 0.185 \\
\hline Respiratory distress, $\mathrm{n}(\%)$ & $0(0 \%)^{\mathrm{c}}$ & $7(15 \%)$ & 0.330 \\
\hline \multicolumn{4}{|l|}{ Termination of pregnancy before 24 weeks, $n(\%)^{d}$} \\
\hline Elective termination & $1(8 \%)$ & $6(13 \%)$ & 1 \\
\hline Termination due to medical complications & $1(8 \%)$ & $5(11 \%)$ & 1 \\
\hline No termination & $10(83 \%)$ & $35(76)$ & 0.716 \\
\hline \multicolumn{4}{|l|}{ Pregnancy outcomes, $\mathrm{n}(\%)^{\mathrm{d}}$} \\
\hline Miscarriage & $4(33 \%)$ & $7(15 \%)$ & 0.214 \\
\hline Intrauterine death & $2(17 \%)$ & $4(9 \%)$ & 0.594 \\
\hline Preterm delivery & $2(17 \%)$ & $18(39 \%)$ & 0.186 \\
\hline Term delivery & $2(17 \%)$ & $6(13 \%)$ & 0.665 \\
\hline Termination of pregnancy & $2(17 \%)$ & $11(24 \%)$ & 0.716 \\
\hline Fetal viability, $\mathrm{n}(\%)$ & $4(33 \%)^{b}$ & $24(52 \%)$ & 0.336 \\
\hline Hysterotomy, n (\%) & $2(18 \%)^{\mathrm{a}}$ & $29(63 \%)$ & 0.015 \\
\hline Peripartum hysterectomy, $\mathrm{n}(\%)$ & $2(18 \%)^{\mathrm{a}}$ & $7(15 \%)$ & 1 \\
\hline Time to hCG regression, weeks, median (minimum-maximum) & $16.14(5.42-86)^{\mathrm{a}}$ & $12(5-33.14)^{\mathrm{e}}$ & 0.186 \\
\hline GTN progression, $\mathrm{n}(\%)$ & $5(42 \%)^{b}$ & $21(47 \%)^{\mathrm{b}}$ & 1 \\
\hline FIGO anatomic staging, median (minimum-maximum) & $1(1-3)$ & $1(1-3)$ & 1 \\
\hline FIGO prognostic staging, median (minimum-maximum) & $1(0-5)^{\mathrm{b}}$ & $3(0-8)$ & 1 \\
\hline hCG levels at GTN diagnosis, mIU/mL, median (minimum-maximum) & $14,327(9-76,644)^{\mathrm{b}}$ & $15,000(32-137,285)$ & 0.979 \\
\hline Resistant GTN, n (\%) & $1(25 \%)$ & $2(9 \%)$ & 0.488 \\
\hline Recurrent GTN, n (\%) & $2(50 \%)$ & $1(5 \%)$ & 0.056 \\
\hline Potentially life-threatening conditions, n (\%) & $3(30 \%)^{a}$ & $29(63 \%)$ & 0.045 \\
\hline Absolute number of potentially life-threatening conditions events & 5 & 69 & \\
\hline Maternal near miss events, $\mathrm{n}(\%)$ & $0(0 \%)^{\mathrm{a}}$ & $10(22 \%)$ & 0.180 \\
\hline Absolute number of maternal near miss events & 0 & 22 & \\
\hline Death, $\mathrm{n}(\%)$ & $0(0 \%)^{\mathrm{b}}$ & $1(2 \%)$ & 1 \\
\hline
\end{tabular}

hCG: human chorionic gonadotropin hormone; GTN: gestational trophoblastic neoplasia.

a Information not available in 2 patients.

b Information not available in 1 patient.

c Information not available in 3 patients.

d Information not available in 1 patient in the NETDC series.

e Information not available in 4 patients.

disparity could be the reflection of different disease behavior, possibly driven by genetic and environmental factors of regional location, which can seen in other models of disease [18]. It is also possible that after the diagnosis of a medical complication such as preeclampsia, the speed and intensity of medical intervention may vary in different healthcare systems. Furthermore, in Brazil there may be delays of patients in seeking care until extreme situations.

Analysing the cases in NETDC over the past 5 decades, there was no significant shift in disease presentation unlike that seen in singleton complete moles [10]. Even with the evident progress in perinatal medicine over the years, an improvement of obstetric outcomes of CHMCF was not observed, supporting the notion that a determining factor in CHMCF could be related to trophoblastic biology and not simply the management of the disease.

Some of the main questions addressed when caring for a patient with $\mathrm{CHMCF}$ are the possibility of reaching fetal viability, possible medical complications and the risk of GTN. The literature reports a chance of delivering a viable infant varying from 20 to $71 \%$, when not taking electively terminated pregnancies into account (Table 5) [4,6-9,19-22].
This study found a $60 \%$ chance of delivering a viable fetus if expectant management is adopted for $\mathrm{CHMCF}$. There were no cases of intrauterine death after 24 weeks, suggesting that there is no need to induce delivery after viability without an obvious maternal or fetal indication. Most studies in the literature report a similar rate of spontaneous abortion and intrauterine death between 20 and 30\% [4,6-9,19-22].

The rate of medical complications (63\%) and potentially life-threatening conditions (56\%) were quite high in the overall data; however the need to medically terminate the pregnancy was $10 \%$. The need for pregnancy termination due to medical complications in the literature varies between 0 and 71\%, since the utilization of this method may depend on multiple factors, including the social and cultural acceptance of this practice in a particular setting and the resources of the hospital involved in the care of CHMCF (Table 5) [4,6-9,19-22]. Compared to single complete moles in a similar time period, $\mathrm{CHMCF}$ in this study presented with significantly higher rates of preeclampsia, clinical hyperthyroidism, potentially life-threatening conditions and maternal near miss events. The only maternal death in this cohort was caused by a severe acute respiratory insufficiency during a medical termination of 


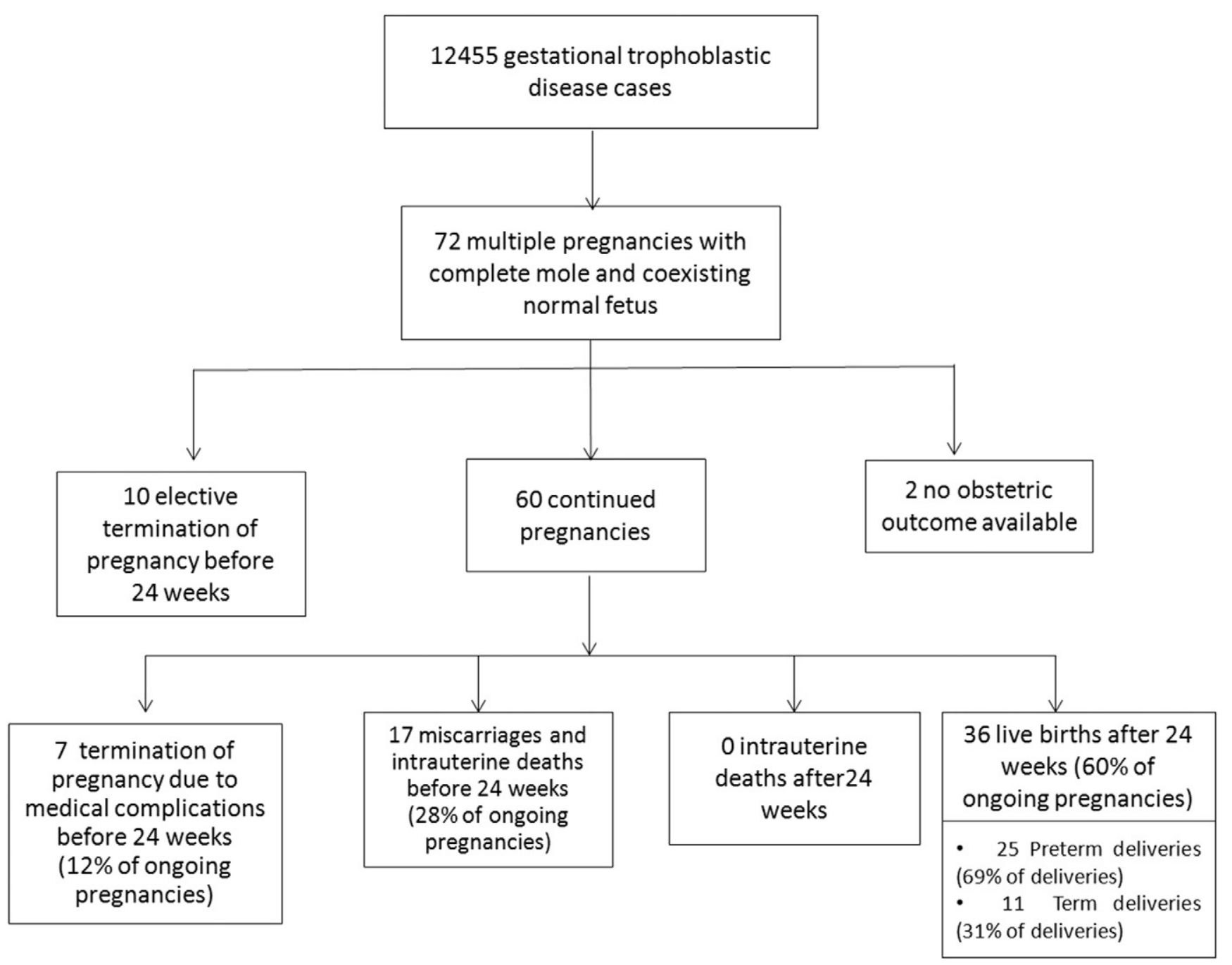

Fig. 1. Overview of the study population and obstetric outcomes.

pregnancy due to severe preeclampsia; death was likely caused by a massive trophoblastic embolization associated with pulmonary edema. Across the studies in the literature, the frequency of clinical complications are variable, possibly due to different classification of the conditions and availability of the retrieved data, since some of the centers were not directly involved in the care of the pregnancy. The rate of vaginal hemorrhage in this study (59\%) was higher than the other studies in the literature (14-34\%) because we did not limit this definition to only the severe cases that led to termination of pregnancy $[6,7,22]$. The frequency of hyperthyroidism of this study was lower (14\%) than reported by others in the literature (28-50\%) due to the fact that only cases with clinical signs were included in the analysis and not all of those with laboratory finding of thyroid hormonal unbalance $[7,20,22]$. The preeclampsia rate in the literature ranges from $3 \%$ to $40 \%$, and this study is within this range (32\%) $[4,6-9,19,20,22]$. Since not all studies provided the definition used for preeclampsia the interpretation of the variability of this finding was limited; some studies only had the information of this complication leading to pregnancy termination, which would represent a much lower rate than the overall preeclampsia rate. In the study by Kihara et al., preeclampsia was found to be a factor associated with poor fetal outcome; however this finding was not seen in this study, since the presence of preeclampsia was not associated with fetal viability ( $\mathrm{p}=0.775$ ) [19].

Another controversial issue lies in the risk of CHMCF progressing to GTN. The studies in the literature reported a GTN rate between 14 and
57\% (Table 5) [1,4,6-9,19-22]. The largest study regarding this matter is from the Charing Cross and Weston Park Trophoblastic Disease Centers, which included 90 cases of CHMCF with a risk of $27 \%$ for GTN, slightly higher than single complete moles [9]. A national survey conducted by Matsui et al. [6], also reported an increased GTN rate (31\%) across 72 cases of CHMCF in Japan. The current study showed a higher risk (46\%) when compared to single complete moles (18\%) in a similar time period [5]. This disparity could be explained by at least two reasons: an actual different disease behavior or due to overrepresentation of GTN cases in a referral center versus population-based data. However, given the rarity and the doubts in the management of CHMCF, patients who are recognized to have this condition will tend to be treated in a referral center.

Similar to the findings in the Charing Cross experience, the present study did not find any difference related to elective terminations of pregnancy and GTN rate, confirming that the decision to terminate a CHMCF should not be based on the risk of developing GTN [1]. A striking finding in this study was the association between GTN and the need for medical termination due to severe complications and higher hCG levels at the end of pregnancy. The production of hCG reflects the behavior of trophoblastic cells and particularly high hCG levels are considered a marker of high-risk for developing GTN. In CHMCF, an increasing hCG trend during pregnancy was associated with poorer fetal outcome, as the fall of hCG levels may be correlated with the shrinkage of the molar mass $[19,22,23]$. The results suggest that trophoblastic cell 
Table 3

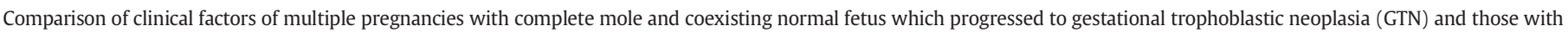
spontaneous remission in all time periods and Referral Centers.

\begin{tabular}{|c|c|c|c|}
\hline & $\mathrm{GTN}^{\mathrm{a}}$ & Regression & $\mathrm{p}$ value \\
\hline Number of cases & 31 & 37 & \\
\hline Age, median (minimum-maximum) & $30(18-41)$ & $27(18-41)^{\mathrm{b}}$ & 0.054 \\
\hline Gravidity, median (minimum-maximum) & $2(1-5)^{\mathrm{b}}$ & $2(1-5)$ & 0.522 \\
\hline Parity, median (minimum-maximum) & $0(0-4)^{\mathrm{b}}$ & $0(0-4)$ & 0.960 \\
\hline Previous mole, $\mathrm{n}(\%)$ & $1(3 \%)^{b}$ & $2(5 \%)$ & 1 \\
\hline Assisted reproduction treatment, $\mathrm{n}(\%)$ & $5(16 \%)$ & $4(11 \%)$ & 0.500 \\
\hline Gestational age at the end of pregnancy, weeks, median (minimum-maximum) & $17(11-39)^{\mathrm{c}}$ & $28.5(11-40)^{\mathrm{b}}$ & 0.002 \\
\hline hCG levels at end of pregnancy, mIU/mL, median (minimum-maximum) & $250,000(33,648-1,670,600)^{d}$ & $120,000(1048-1,365,080)^{\mathrm{e}}$ & 0.026 \\
\hline Medical complications, $\mathrm{n}(\%)$ & $18(64 \%)^{f}$ & $22(65 \%)^{\mathrm{f}}$ & 1 \\
\hline \multicolumn{4}{|l|}{ Termination of pregnancy before 24 weeks, $\mathrm{n}(\%)^{\mathrm{g}}$} \\
\hline Elective termination & $7(23 \%)$ & $3(8 \%)$ & 0.098 \\
\hline Termination due to medical complications & $6(20 \%)$ & $0(0 \%)$ & 0.006 \\
\hline No termination & $17(57 \%)$ & $34(92 \%)$ & 0.001 \\
\hline \multicolumn{4}{|l|}{ Pregnancy outcomes, $\mathrm{n}(\%)^{\mathrm{g}}$} \\
\hline Miscarriage & $8(27 \%)$ & $3(8 \%)$ & 0.095 \\
\hline Intrauterine death & $1(3 \%)$ & $5(13 \%)$ & 0.213 \\
\hline Preterm delivery & $7(23 \%)$ & $18(49 \%)$ & 0.043 \\
\hline Term delivery & $1(3 \%)$ & $8(22 \%)$ & 0.035 \\
\hline Termination of pregnancy & $13(43 \%)$ & $3(8 \%)$ & 0.001 \\
\hline Fetal viability, $\mathrm{n}(\%)$ & $8(27 \%)^{b}$ & $25(68 \%)^{b}$ & 0.004 \\
\hline Hysterotomy, n (\%) & $13(43 \%)$ & $19(53 \%)^{b}$ & 0.470 \\
\hline Peripartum hysterectomy, n (\%) & $3(10 \%)$ & $6(17 \%)^{b}$ & 0.494 \\
\hline Potentially life-threatening conditions, n (\%) & $17(59 \%)^{\mathrm{c}}$ & $18(53 \%)^{\mathrm{h}}$ & 0.800 \\
\hline Maternal near miss events, $\mathrm{n}(\%)$ & $5(17 \%)^{c}$ & $4(12 \%)^{\mathrm{h}}$ & 0.721 \\
\hline
\end{tabular}

hCG: human chorionic gonadotropin hormone; GTN: gestational trophoblastic neoplasia.

a GTN progression was not available in 4 cases.

b Information not available in 1 patient.

c Information not available in 2 patients.

d Information not available in 5 patients.

e Information not available in 7 patients.

${ }^{f}$ Information not available in 7 patients.

$\mathrm{g}$ Information not available in 1 patient in the GTN group.

$\mathrm{h}$ Information not available in 3patients.

biology may influence clinical presentation and behavior of disease and more aggressive molar pregnancies would have a higher likelihood to developing GTN [24].

The strengths of this study are the sample size, the availability of information on pregnancy related events and the possibility of evaluating different regional settings by the same research team. One of the limitations of this study was its retrospective nature, however due to the rarity of CHMCF it is not feasible to perform a prospective study. Due to the extensive period of time evaluated at the NETDC there was substantial missing data, especially from the older cases which date back to 1966 , limiting statistical comparisons and interpretation. One of the weaknesses of the study design was the fact that data was collected from different centers, possibly with unequal resources and heterogeneous CHMCF management; although all centers are University tertiary hospitals with a specialized multiprofessional team in Trophoblastic Disease and Maternal Fetal Medicine.

In summary, the current study indicates that there might be a difference in disease presentation of CHMCF between geographical locations that could be explained by regional disparities. Importantly, $60 \%$ of the patients with expectant management of their CHMCF delivered a viable

Table 4

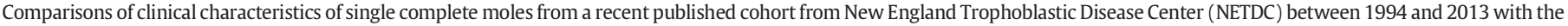
combined data from NETDC and Brazilian Trophoblastic Disease Centers (BTDC) on multiple pregnancies with complete mole and coexisting normal fetus (CHMCF) (1990-2015).

\begin{tabular}{|c|c|c|c|}
\hline & Single moles NETDC 1994-2013 & CHMCF in NETDC \& BTDC 1990-2015 & $\mathrm{p}$ value \\
\hline Number of cases & 194 & 59 & \\
\hline Age, median (minimum-maximum) & $30(22-35)$ & $29(18-41)$ & 0.872 \\
\hline Gravidity, median (minimum-maximum) & $2(1-10)$ & $2(1-5)$ & 0.048 \\
\hline Parity, median (minimum-maximum) & $1(0-8)$ & $0(0-4)$ & 0.395 \\
\hline Gestational age at diagnosis, weeks, median (minimum-maximum) & $9(5-22)^{a}$ & $15(9-23)^{b}$ & $<0.001$ \\
\hline Gestational age at the end of pregnancy, weeks, median (minimum-maximum) & $9(5-22)^{a}$ & $23(11-40)$ & $<0.001$ \\
\hline hCG levels at diagnosis, $\mathrm{mIU} / \mathrm{mL}$, median (minimum-maximum) & $164,579(183-4,718,955)^{\mathrm{c}}$ & $400,000(2545-2,052,500)^{\mathrm{d}}$ & $<0.001$ \\
\hline hCG levels at end of pregnancy, mIU/mL, median (minimum-maximum) & $164,579(183-4,718,955)^{\mathrm{c}}$ & $200,000(18,361-1,670,600)^{d}$ & 0.161 \\
\hline Preeclampsia, n (\%) & $2(1 \%)$ & $18(32 \%)^{\mathrm{e}}$ & $<0.001$ \\
\hline Clinical hyperthyroidism, n (\%) & $4(2 \%)$ & $9(16 \%)^{\mathrm{e}}$ & $<0.001$ \\
\hline GTN progression, $\mathrm{n}(\%)$ & $34(18 \%)^{f}$ & $26(46 \%)^{b}$ & $<0.001$ \\
\hline Potentially life-threatening conditions, $\mathrm{n}(\%)$ & $4(2)$ & $32(56)^{\mathrm{b}}$ & $<0.001$ \\
\hline Maternal near miss events, $\mathrm{n}(\%)$ & $0(0)$ & $10(17)^{\mathrm{b}}$ & $<0.001$ \\
\hline
\end{tabular}

hCG: human chorionic gonadotropin hormone; GTN: gestational trophoblastic neoplasia.

a Information not available in 17 patients.

b Information not available in 2 patients.

c Information not available in 13 patients.

d Information not available in 6 patients.

e Information not available in 3 patients.

${ }^{\mathrm{f}}$ Information not available in 6 patients and 2 patients were excluded for prophylactic chemotherapy. 
Table 5

Major studies reporting clinical presentation and outcomes of multiple pregnancies with complete mole and coexisting normal fetus.

\begin{tabular}{|c|c|c|c|c|c|c|c|c|c|c|}
\hline & $\begin{array}{l}\text { Matsui et al. } \\
{[6]}\end{array}$ & $\begin{array}{l}\text { Kihara et } \\
\text { al. [19] }\end{array}$ & $\begin{array}{l}\text { Lee et al. } \\
{[22]}\end{array}$ & $\begin{array}{l}\text { Kutuk et al. } \\
{[20]}\end{array}$ & $\begin{array}{l}\text { Niemann } \\
\text { et al. [8] }\end{array}$ & $\begin{array}{l}\text { Massardier } \\
\text { et al. [7] }\end{array}$ & $\begin{array}{l}\text { Niemann } \\
\text { et al. [9] }\end{array}$ & $\begin{array}{l}\text { Wee \& } \\
\text { Jauniaux [4] }\end{array}$ & $\begin{array}{l}\text { Fishman et } \\
\text { al. [21] }\end{array}$ & $\begin{array}{l}\text { Lin et al. } \\
(2017)^{\mathrm{d}}\end{array}$ \\
\hline Number of cases & 18 and $72^{\mathrm{a}}$ & 15 & 6 & 7 & 8 & 14 & 90 & 8 & 7 & 72 \\
\hline Time frame & NA & 1991-2011 & $1998-2008$ & 2007-2012 & 1986-2003 & 1999-2006 & 1998-2011 & 1996-2004 & 1966-1997 & 1966-2016 \\
\hline Setting & $\begin{array}{l}\text { Japan - } \\
\text { national } \\
\text { survey }\end{array}$ & $\begin{array}{l}\text { Japan - } \\
\text { Chiba }\end{array}$ & $\begin{array}{l}\text { Korea - } \\
\text { Seoul }\end{array}$ & Turkey & Denmark & France-Lyon & $\begin{array}{l}\text { UK-Charing Cross \& } \\
\text { Weston Park } \\
\text { Hospitals }\end{array}$ & $\begin{array}{l}\text { UK - UCLH } \\
\& \mathrm{KCH}\end{array}$ & $\begin{array}{l}\text { USA - } \\
\text { Chicago }\end{array}$ & $\begin{array}{l}\text { USA - } \\
\text { Boston \& } \\
\text { Brazil }\end{array}$ \\
\hline Vaginal hemorrhage, n (\%) & $3(17 \%)^{b}$ & NA & $2(34 \%)^{b}$ & NA & $0(0 \%)$ & $2(14 \%)^{b}$ & NA & NA & NA & $37(59 \%)$ \\
\hline Preeclampsia, n (\%) & $5(28 \%)^{b}$ & $6(40 \%)$ & $1(17 \%)$ & $1(14 \%)$ & $0(0 \%)$ & $4(29 \%)$ & $3(3 \%)^{\mathrm{b}}$ & $1(12 \%)$ & NA & $20(32 \%)$ \\
\hline Hyperthyroidism, n (\%) & NA & NA & $3(50 \%)$ & $2(28 \%)$ & $0(0 \%)$ & $4(29 \%)$ & $\mathrm{NA}$ & NA & NA & $9(14 \%)$ \\
\hline Elective TOP, n (\%) & $5(28 \%)$ & $2(28 \%)$ & $1(17 \%)$ & $2(28 \%)$ & $5(62 \%)$ & $3(21 \%)$ & $39(43 \%)^{\mathrm{e}}$ & $1(12 \%)$ & $0(0 \%)$ & $10(14 \%)$ \\
\hline $\begin{array}{l}\text { TOP due to maternal } \\
\text { complications, n (\%) }\end{array}$ & $8(44 \%)$ & $0(0 \%)$ & $2(34 \%)$ & $0(0 \%)$ & $0(0 \%)$ & $4(29 \%)$ & $5(6 \%)$ & $0(0 \%)$ & $5(71 \%)$ & $7(10 \%)$ \\
\hline $\begin{array}{l}\text { Miscarriage or intrauterine } \\
\text { death, } \mathrm{n}(\%)\end{array}$ & $2(11 \%)$ & $4(57 \%)$ & $2(34 \%)$ & $2(25 \%)$ & $2(25 \%)$ & $3(21 \%)$ & $17(19 \%)^{f}$ & $2(25 \%)$ & NA & $17(24 \%)$ \\
\hline Preterm delivery, n (\%) & $1(6 \%)$ & $1(14 \%)$ & 0 & $1(12 \%)$ & $1(12 \%)$ & $3(21 \%)$ & NA & $2(25 \%)$ & $2(28 \%)$ & $25(36 \%)$ \\
\hline Term delivery, $\mathrm{n}(\%)$ & $2(11 \%)$ & $0(0 \%)$ & $1(17 \%)$ & $0(0 \%)$ & $0(0 \%)$ & $1(7 \%)$ & NA & $\begin{array}{l}3 \text { of } 8 \\
(37 \%)\end{array}$ & $0(0 \%)$ & $11(16 \%)$ \\
\hline $\begin{array}{l}\text { Delivery of a viable infant in } \\
\text { ongoing pregnancy, } \mathrm{n}(\%)\end{array}$ & $\begin{array}{l}3 \text { of } 13 \\
(23 \%)\end{array}$ & $\begin{array}{l}1 \text { of } 5 \\
(20 \%)\end{array}$ & $\begin{array}{l}1 \text { of } 5 \\
(20 \%)\end{array}$ & $\begin{array}{l}1 \text { of } 3 \\
(34 \%)\end{array}$ & $\begin{array}{l}1 \text { of } 3 \\
(34 \%)\end{array}$ & $\begin{array}{l}3 \text { of } 11 \\
(27 \%)\end{array}$ & 29 of $51(57 \%)$ & $\begin{array}{l}5 \text { of } 7 \\
(71 \%)\end{array}$ & $\begin{array}{l}2 \text { of } 7 \\
(28 \%)\end{array}$ & $\begin{array}{l}36 \text { of } 60 \\
(60 \%)\end{array}$ \\
\hline GTN progression, $\mathrm{n}(\%)$ & $\begin{array}{l}9 \text { of } 18 \\
(50 \%) \\
22 \text { of } 72 \\
(31 \%)\end{array}$ & $1(14 \%)$ & $3(50 \%)$ & $1(14 \%)$ & $2(25 \%)$ & $7(50 \%)$ & $24(27 \%)$ & $3(37 \%)$ & $4(57 \%)$ & $31(46 \%)$ \\
\hline
\end{tabular}

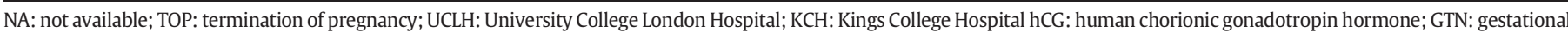
trophoblastic neoplasia.

a The study by Matsui et al. [6] included analysis of 72 cases in the GTN progression rate and 18 cases for pregnancy presentation and outcomes.

b Need for termination of pregnancy.

d Missing data for clinical complications in 9 patients, for pregnancy outcomes in 2 patients and GTN progression in 4 patients.

e The data on electively terminated pregnancies from the study by Niemann et al. [9] is mixed with cases of spontaneous miscarriages before 14 weeks.

${ }^{\mathrm{f}}$ Data on miscarriages and intrauterine deaths in the study by Niemann et al. [9] accounts only those that occurred after 14 weeks.

infant. Elective termination of pregnancy did not influence the risk for GTN progression; however the need for termination of pregnancy due to medical complications and higher hCG levels were associated with development of GTN in CHMCF. These findings should contribute to a better understanding of the natural history and management of CHMCF.

\section{Conflict of interest}

The authors declare no conflict of interest regarding the publication of this research.

\section{Financial support}

We wish to acknowledge the support of the Donald P. Goldstein, MD Trophoblastic Tumor Registry Endowment; the Dyett Family Trophoblastic Disease Research and Registry Endowment; University of Sao Paulo; and Carlos Chagas Filho Foundation for Research Support in the State of Rio de Janeiro/Brazil (FAPERJ) - an agency under the Brazilian Ministry of Science and Technology (AB). The funding agencies had no direct role in the generation of the data or the manuscript.

\section{Appendix A. Supplementary data}

Supplementary data to this article can be found online at http://dx. doi.org/10.1016/j.ygyno.2017.01.021.

\section{References}

[1] N.J. Sebire, M. Foskett, F.J. Paradinas, R.A. Fisher, R.J. Francis, D. Short, E.S. Newlands, M.J. Seckl, Outcome of twin pregnancies with complete hydatidiform mole and healthy co-twin, Lancet 359 (2002) 2165-2166.

[2] M.A. Steller, D.R. Genest, M.R. Bernstein, J.M. Lage, D.P. Goldstein, R.S. Berkowitz, Natural history of twin pregnancy with complete hydatidiform mole and coexisting fetus, Obstet. Gynecol. 83 (1994) 35-42, http://dx.doi.org/10.1016/00207292(94)90494-4.
[3] L.O. Vejerslev, Clinical management and diagnostic possibilities in hydatidiform mole with coexistent fetus, Obstet. Gynecol. Surv. 46 (1991) 577-588.

[4] L. Wee, E. Jauniaux, Prenatal diagnosis and management of twin pregnancies complicated by a co-existing molar pregnancy, Prenat. Diagn. 25 (2005) 772-776 http://dx.doi.org/10.1002/pd.1272.

[5] S.Y. Sun, A. Melamed, N.T. Joseph, A.A. Gockley, D.P. Goldstein, M.R. Bernstein, N.S. Horowitz, R.S. Berkowitz, Clinical presentation of complete hydatidiform mole and partial hydatidiform mole at a regional trophoblastic disease center in the United States over the past 2 decades, Int. J. Gynecol. Cancer 26 (2016) 367-370, http:// dx.doi.org/10.1097/IGC.0000000000000608.

[6] H. Matsui, S. Sekiya, T. Hando, N. Wake, Y. Tomoda, Hydatidiform mole coexistent with a twin live fetus: a national collaborative study in Japan, Hum. Reprod. 15 (2000) 608-611, http://dx.doi.org/10.1016/S0020-7292(00)83458-X.

[7] J. Massardier, F. Golfier, D. Journet, L. Frappart, M. Zalaquett, A.M. Schott, V.T. Lenoir, O. Dupuis, T. Hajri, D. Raudrant, Twin pregnancy with complete hydatidiform mole and coexistent fetus. Obstetrical and oncological outcomes in a series of 14 cases, Eur. J. Obstet. Gynecol. Reprod. Biol. 143 (2009) 84-87, http://dx.doi.org/10.1016/ j.ejogrb.2008.12.006.

[8] I. Niemann, L. Sunde, L.K. Petersen, Evaluation of the risk of persistent trophoblastic disease after twin pregnancy with diploid hydatidiform mole and coexisting normal fetus, Am. J. Obstet. Gynecol. 197 (2007) 1-5, http://dx.doi.org/10.1016/j.ajog.2007. 02.038.

[9] I. Niemann, R. Fisher, N. Sebire, M. Wells, D. Short, J. Tidy, B. Hancock, R. Coleman, P. Savage, M. Seckl, Update on UK outcomes for women with twin pregnancies comparimising a complete hydatidiform mole (CHM) and a normal co-twin, XVII World Congr. Gestation. Trophobl. Dis 2013, p. 57 (abstract).

[10] S.Y. Sun, A. Melamed, D.P. Goldstein, M.R. Bernstein, N.S. Horowitz, A.F. Moron, I. Maesta, A. Braga, R.S. Berkowitz, Changing presentation of complete hydatidiform mole at the New England Trophoblastic Disease Center over the past three decades: does early diagnosis alter risk for gestational trophoblastic neoplasia? Gynecol. Oncol. 138 (2015) 46-49, http://dx.doi. org/10.1016/j.ygyno.2015.05.002.

[11] R.R. Soares, I. Maestá, J. Colón, A. Braga, A. Salazar, R.C. Charry, S.Y. Sun, D.P. Goldstein, R.S. Berkowitz, Complete molar pregnancy in adolescents from North and South America: clinical presentation and risk of gestational trophoblastic neoplasia, Gynecol. Oncol. 2016 (2016) 496-500, http://dx.doi.org/10.1016/j.ygyno. 2016.07.002.

[12] E. von Elm, D. Altman, M. Egger, S. Pocock, P. Gøtzsche, J. Vandenbroucke, STROBE Initiative, The Strengthening the Reporting of Observational Studies in Epidemiology (STROBE) statement: guidelines for reporting observational studies, Lancet 370 (9596) (Oct 20, 2007) 1453-1457.

[13] L. Say, J.P. Souza, R.C. Pattinson, Maternal near miss - towards a standard tool for monitoring quality of maternal health care, Best Pract. Res. Clin. Obstet. Gynecol. 23 (2009) 287-296, http://dx.doi.org/10.1016/j.bpobgyn.2009.01.007. 
[14] World Health Organization, WHO Recommendations on Interventions to Improve Preterm Birth Outcomes, https://www.ncbi.nlm.nih.gov/pubmed/264472642015.

[15] H.Y.S. Ngan, E.I. Kohorn, L.A. Cole, R.J. Kurman, S.J. Kim, J.R. Lurain, M.J. Seckl, S Sasaki, J.T. Soper, Trophoblastic disease, Int. J. Gynecol. Obstet. 119 (2012) S130-S136, http://dx.doi.org/10.1016/S0020-7292(12)60026-5 (Suppl.).

[16] S.Y. Sun, D.P. Goldstein, M.R. Bernstein, N.S. Horowitz, R. Mattar, I. Maesta, A. Braga, R.S. Berkowitz, Maternal near miss according to world health organization classification among women with a hydatidiform mole: experience at the New England Trophoblastic Disease Center, 1994-2013, J. Reprod. Med. 61 (2016) 210-214.

[17] M.S.F.S. Cagayan, Hydatidiform mole and its complications: review of patient profiles and management at the University of the Philippines - Philippine General Hospital, J. Reprod. Med. (2014) 235-240 0024-7758/14/5905-06-235/\$18.00/0.

[18] P. Elliott, N. Best, Geographic patterns of disease, Wiley StatsRef Stat. Ref. Online 2014, pp. 1-7.

[19] M. Kihara, H. Usui, H. Tanaka, H. Inoue, H. Matsui, M. Shozu, Complicating preeclampsia as a predictor of poor survival of the fetus in complete hydatidiform mole coexistent with twin fetus, J. Reprod. Med. 57 (2012) 325-328.
[20] M.S. Kutuk, M.T. Ozgun, M. Dolanbay, C. Batukan, S. Uludag, M. Basbug, Sonographic findings and perinatal outcome of multiple pregnancies associating a complete hydatidiform mole and a live fetus: a case series, J. Clin. Ultrasound 42 (2014) 465-471, http://dx.doi.org/10.1002/jcu.22169.

[21] D.A. Fishman, L.A. Padilla, P. Keh, L. Cohen, M. Frederiksen, J.R. Lurain, Management of twin pregnancies consisting of a complete hydatidiform mole and normal fetus, Obstet. Gynecol. 91 (1998) 546-550, http://dx.doi.org/10.1016/S00297844(97)00720-5.

[22] S.W. Lee, M.Y. Kim, J.H. Chung, J.H. Yang, Y.H. Lee, Y.K. Chun, Clinical findings of multiple pregnancy with a complete hydatidiform mole and coexisting fetus, J. Ultrasound Med. 29 (2010) 271-280.

[23] M. Okumura, K. Fushida, R. Francisco, R. Schultz, M. Zugaib, Massive necrosis of a complete hydatidiform mole in a twin pregnancy with a surviving coexistent fetus, J. Ultrasound Med. 33 (2014) 177-179, http://dx.doi.org/10.7863/ultra.33.1. 177.

[24] R.S. Berkowitz, D.P. Goldstein, Clinical practice. Molar pregnancy, N. Engl. J. Med. 360 (2009) 1639-1645, http://dx.doi.org/10.1097/01.SA.0000358600.18446.e2. 